\title{
Three new andean species of Drosophila (Diptera, Drosophilidae) of the mesophragmatica group
}

\author{
Doris Vela \& Violeta Rafael
}

Laboratorio de Genética Evolutiva, Escuela de Ciencias Biológicas, Pontificia Universidad Católica del Ecuador, 17- 01-2184, Quito, Ecuador.

\begin{abstract}
Three new species of mesophragmatica group, Drosophila amaguana, Drosophila shyri and Drosophila ruminahuii from Pasochoa Forest Reserve, northern Ecuadorian Andes, are described. The two subgroups currently composing the mesophragmatica group are renamed as the mesophragmatica subgroup to which the first two species have been added, and the viracochi subgroup to which the latter species has been added. These subgroups are defined based on the direction of the basal scutellar setae, which are divergent in the species of the former subgroup and convergent in the latter.
\end{abstract}

KEYWORDS. Ecuador, mesophragmatica subgroups, viracochi subgroup, new species.

\section{INTRODUCTION}

Nine species of Drosophila Fallén, 1823 were known in the mesophragmatica group (VILELA \& BäCHLI, 1990): D. altiplanica Brncic \& Koref-Santibañez, 1957; D. brncici Hunter \& Hunter, 1964; D. canescens Duda, 1927; D. gasici Brncic, 1957; D. gaucha Jaeger \& Salzano, 1953; D. mesophragmatica Duda, 1927; D. orkui Brncic \& Koref-Santibañez, 1957; D. pavani Brncic, 1957; D. viracochi Brncic \& Koref-Santibañez, 1957. A tenth species, Drosophila camaronensis Brncic, 1957, was recently added to the group (VILELA \& Bächl, 2002). Distribution of all these species, except D. gaucha, which is widely distributed, is restricted to the South American Andes and they represent the most characteristic species complex of this mountainous system (BRNCIC et al., 1971).

Morphological identification of species in the mesophragmatica group is difficult given their notable morphological similarities. This is well exemplified in the sibling pair of species D. gaucha and D. pavani, which are extremely similar regarding both the external features and the male terminalia. Drosophila viracochi can be clearly distinguished since it is one of the two species that presents convergent basal scutellar setae. The direction of the basal scutellar setae is an important taxonomic character. This trait was chosen by NACRUR (1958) to propose the subdivision of the mesophragmatica group into two subgroups: species which belong to subgroup "a" have divergent basal scutellars, whereas those belonging to subgroup " $\mathrm{b}$ " exhibit convergent basal scutellars. BRNCIC et al. (1971), based on cytological and isozyme data of six species, proposed the existence of three lineages of descendants in the mesophragmatica group.

Three new species of the mesophragmatica group are described: $D$. amaguana, $D$. ruminahuii and $D$. shyri. The proposal of NACRUR (1958) is accepted and two subgroups in the mesophragmatica group are recognized and renamed: the mesophragmatica subgroup with eleven species (D. altiplanica, D. amaguana sp. nov., $D$. brncici, D. canescens, D. camaronensis, D. gasici, D. gaucha, D. mesophragmatica, D. orkui, D. pavani, and $D$. shyri sp. nov.) and the viracochi subgroup with two species (D. ruminahuii sp. nov. and $D$. viracochi).

\section{MATERIAL AND METHODS}

During 1996 and 1997, specimens of Drosophila were collected in one-hectare area in the western slopes of the Pasochoa Volcano (Vela \& Rafael, 2001). The Pasochoa $\left(0^{\circ} 28^{\prime} \mathrm{S}, 78^{\circ} 29^{\prime} \mathrm{W}\right)$ is an extinct volcano located in the Pichincha province, about $35 \mathrm{~km}$ south of Quito.

Fermented banana traps were set in the forest using the method described in RAFAEL et al. (2000). An aspirator was used to collect flies, which remained on the branches of shrubs and trees near the traps. Fallen leaves and branches of shrubs were also swept with an entomological net. The flies were then transferred to vials filled with $10 \mathrm{~cm}^{3}$ gelatin-banana media (RAFAEL et al., 2000). In the laboratory, females were individually isolated to eventually produce isofemale lines. Unfortunately, due to various reasons, no isofemale lines were established, hindering additional biological studies. Each fly was analyzed to determine its external morphology, as well as the morphology of its terminalia. The male phallosomal index (VILELA, 1983) was also determined for each fly. The values in parenthesis correspond to the range of the variables measured. Photographs were taken using a microscope equipped with a camera at 10x magnification.

The types and paratypes of the new species are deposited in the Museo de Zoología, Pontificia Universidad Católica del Ecuador, Quito (QCAZ). Some paratypes of new species have been deposited in the American Museum of Natural History (AMNH), New York.

\section{Drosophila amaguana sp. nov.} (Figs. 1-7, 22)

Drosophila amaguana (nomen nudum); RAFAEL \&
VeLA, 2000:88.
Type material. \& Holotype (dissected, terminalia in 
microvial), labelled "D. amaguana $\checkmark$ holotype DVela det. 1999 / Pasochoa, Pichincha-Ecuador DVela col., Jul 1996" (QCAZ). Nine $\sigma$ paratypes (dissected, terminalia in microvials), labelled "D. amaguana o paratype DVela det. 1999 / Pasochoa, Pichincha-Ecuador DVela col., Jul 1997'. Six § paratypes deposited in QCAZ and three in AMNH.

Type locality. ECUADOR, Pichincha: Volcán Pasochoa, $35 \mathrm{~km}$ south of Quito.

Description. Body brown, overall length of adult $6.5 \mathrm{~mm}$. Arista with 4 upper and 2 lower branches, plus terminal fork. Wing length $5.5 \mathrm{~mm}$, wings slightly darkened and $\mathrm{dM}-\mathrm{Cu}$ crossvein darker. Costal index 4.26. Thorax brown pollinose, with the central zone slightly darker, divergent basal scutellars. Abdomen light yellow. Males present two color patterns in the abdomen: some individuals with marginal bands interrupted from the first to the fourth tergite in the dorsal midline (fig. 1); in others the bands are interrupted in the midline only in the first and second tergites (fig. 2).

Male terminalia. Cerci anteriorly fused to epandrium. Hypandrium longer than epandrium. Surstylus non micropubescent, with $10(10-11)$ prensisetae, 8 (6-8) outer peg-like setae and 10 (8-10) inner setae; epandrium with numerous lower setae (figs. 3, 4). Phallosomal index 1.19. Aedeagus shows a bifid apex and a projection that ends in an angular shape in the ventral side. The aedeagus is ventrally membranous and dorsally displays two hooklike projections. Aedeagal apodeme sclerotized, paraphyses with a thorn-shaped sensillum (figs. 5-7, 22).

Etymology. The species is named after Amaguaña, a town next to the Pasochoa volcano.

\section{Drosophila shyri sp. nov.}

(Figs. 8-14, 23) 2000:88

Drosophila shyri (nomen nudum); RAFAel \& Vela,

Type material. o Holotype (dissected, terminalia in microvial), labelled "D. shyri o" holotype DVela det. 1999 / Pasochoa, Pichincha-Ecuador DVela col., Jul 1996" (QCAZ). Seven $\sigma$ paratypes (dissected, terminalia in microvials), labelled “D. shyri o paratype DVela det. 1999 / Pasochoa, Pichincha-
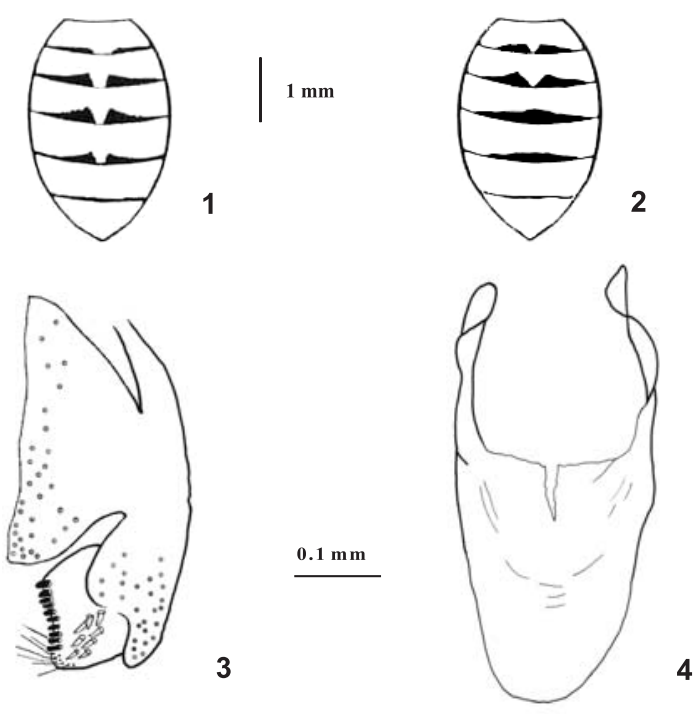

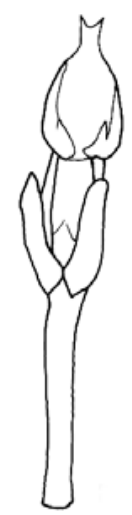

5

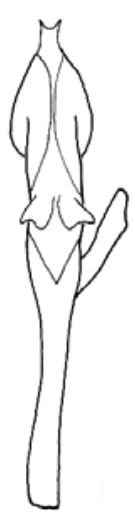

6

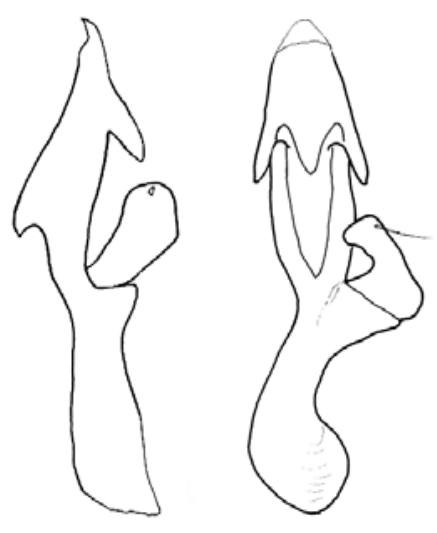

12

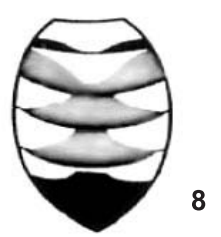
$1 \mathrm{~mm}$

8



10

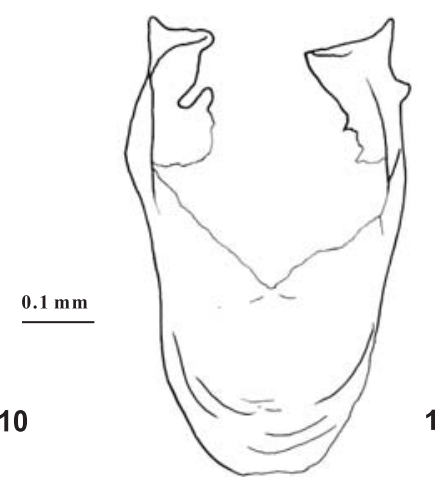

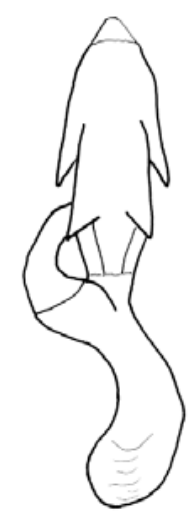

13

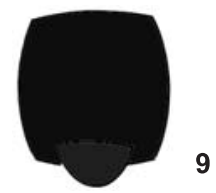

11
Figs. 1-7. Drosophila amaguana sp. nov., male holotype: 1, 2, dimorphic pattern of male abdominal pigmentation; 3, epandrium, cercus and surstylus, posterior view, left side omitted; 4, hypandrium, posterior view; 5-7, aedeagus, aedeagal apodeme and paraphyses, respectively ventral, dorsal and left lateral view.
Figs. 8-14. Drosophila shyri sp. nov., male holotype: 8, pattern of male abdominal pigmentation; 9, pattern of male thorax pigmentation; 10, epandrium, cercus and surstylus, posterior view, left side omitted; 11, hypandrium, posterior view; 12-14, aedeagus, aedegal apodeme and paraphyses, respectively ventral, dorsal and left lateral view. 
Ecuador DVela col., May 1996" and two ひ paratypes, same labels except date (Jun 1996) deposited in QCAZ; three o paratypes, same labels except date (Jul 1997), deposited in AMNH.

Type locality. ECUADOR, Pichincha: Volcán Pasochoa, $35 \mathrm{~km}$ south of Quito.

Description. Body dark, overall length of adult $6.8 \mathrm{~mm}$, dark brown head, dark brown eyes, arista with 4 upper and 2 lower branches, plus terminal fork. Wing length $5.0 \mathrm{~mm}$, slightly dark wing. Costal index 4.71 . Brown pollinose thorax, divergent basal scutellars. Abdomen yellow, the transversal bands in the first and second tergites are interrupted in the midline; in the third, fourth and fifth tergites, the transversal bands are triangular and they spread out laterally; the sixth tergite is dark brown (figs. 8,9).

Male terminalia. Cerci anteriorly fused to epandrium. Hypandrium longer than epandrium. Non micropubescent surstyli, with $12(10-15)$ prensisetae on the right and 15 on the left, outer peg-like setae are absent, and 23 (15$23)$ inner setae to the right and 21 to the left; $22(16-22)$

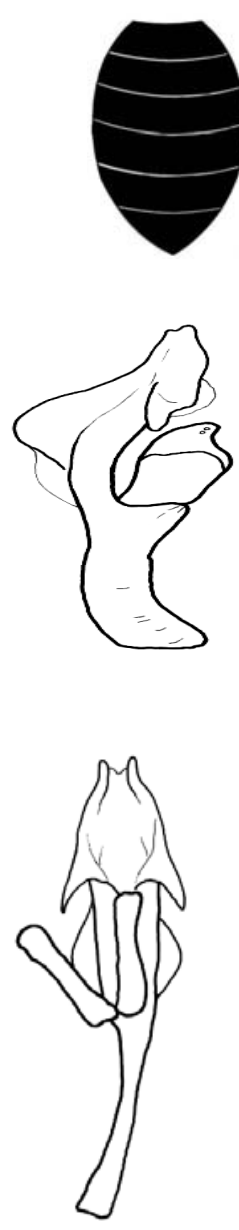

19
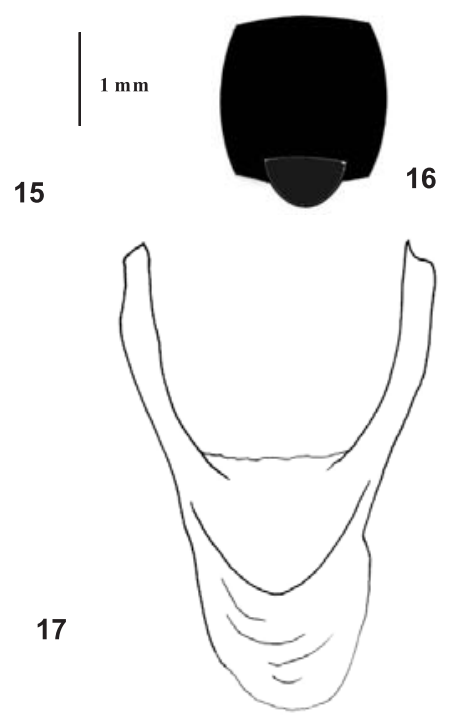

18

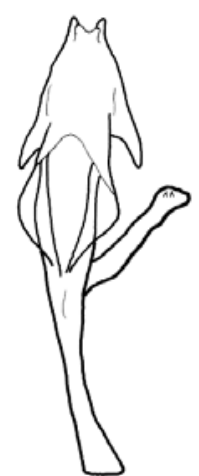

20
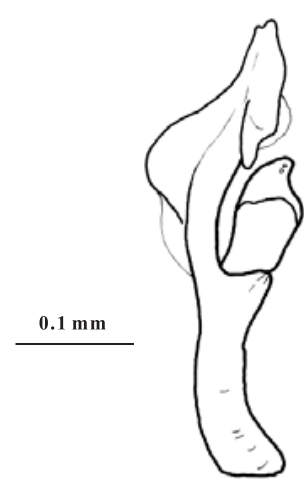

21
Figs. 15-21. Drosophila ruminahuii sp. nov., male holotype: 15, pattern of male abdominal pigmentation; 16 , pattern of male thorax pigmentation; 17, epandrium, cercus and surstylus, posterior view, left side omitted; 18, hypandrium, posterior view; 19-21, aedeagus, aedegal apodeme and paraphyses, respectively ventral, dorsal and left lateral view. setae in the lower area of epandrium (figs. 10, 11). Phallosomal index 1.11. Aedeagus shows a triangular membranous apex, with two triangular projections towards the sides, paraphyses with one projection in the inner surface, aedeagal apodema wide and semimembranous (figs. 12-14, 23).

Etymology. This species is named in honor of a native nation, the Shyris. This ethnic group lived in the northern part of the Ecuadorian mountains until the 15th century.

\section{Drosophila ruminahuii sp. nov.}

(Figs. 15-21, 24)

Drosophila ruminahuii (nomen nudum); RAFAEL \& Vela, 2000:88.

Type material. $\sigma$ Holotype (dissected, terminalia in microvial), labelled " $D$. ruminahuii $\$$ holotype DVela det. 1999 I Pasochoa, Pichincha-Ecuador DVela col., Jul 1997" (QCAZ).

Type locality. ECUADOR, Pichincha: Pasochoa volcano, $35 \mathrm{~km}$ south of Quito.

Description. Body dark brown. Wing length $3.0 \mathrm{~mm}$, the $\mathrm{dM}-\mathrm{Cu}$ crossvein is shaded. Thorax shining brown, convergent basal scutellars. Abdomen shining black (figs. $15,16)$

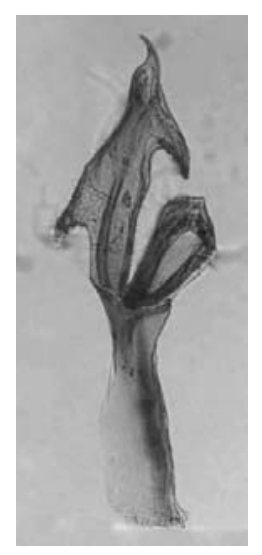

22

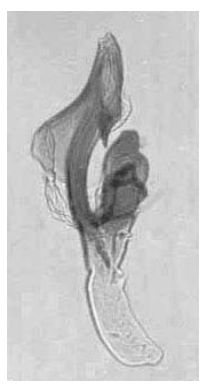

24

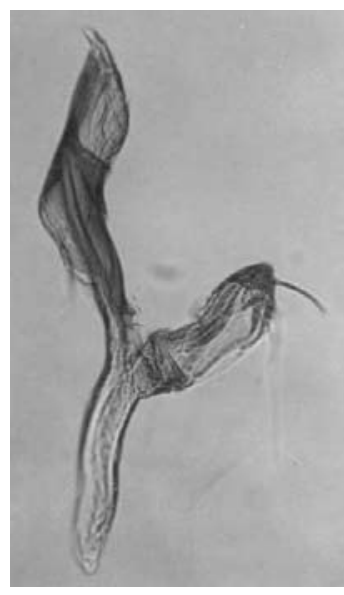

23
Figs. 22-24. Aedeagus, aedeagal apodeme and paraphyses in left lateral view: 22, Drosophila amaguana sp. nov., male holotype; 23, Drosophila shyri sp. nov., male holotype; 24, Drosophila ruminahuii sp. nov., male holotype. 
Male terminalia. Cerci anteriorly fused to epandrium. Hypandrium longer than epandrium. Surstylus non micropubescent with 10 prensisetae, outer peg-like setae absent, and 9 inner setae; epandrium microtrichose with many setae in the lower area (figs. 17, 18). Phallosomal index 1.24. Aedeagus has four tiny projections in the apical zone, the two ventral ones are sharp and highly sclerotized, while the two dorsal ones are like blunt ridges and less sclerotized. In the ventral part of the aedeagus there are two long sclerotized projections; the middle part shows a membranous area, and the dorsal part presents a very pronounced hump-like projection; paraphyses semirectangular, with two bristles in the dorsodistal part, which is narrower (figs. 19-21, 24).

Etymology. The species is named in honor of Rumiñahui, an indigenous hero who bravely fought against the Spaniards in the 1500's.

\section{DISCUSSION}

Thirteen species are know in the mesophragmatica group, all of them are endemic to South America. In Ecuador, in previous collections in Pichincha province, D. mesophragmatica, D. pavani and D. gaucha have been found living in simpatry (RAFAEL et al., 2000; RAFAEL \& Vela, 2000). In the Ecuadorian Andes, the mesophragmatica group inhabits the ravines and humid precipices of the inter-andean valleys as well as the mountain forests, such as the Pasochoa forest, in which four species (D. amaguana, D. shyri, D. ruminahuii and D. mesophragmatica) have been recorded. This group has the second highest species richness in the Pasochoa, after the tripunctata group, with nine species (Vela \& RAFAEL, 2001). Taking into account the three new species, it is possible to assert that Ecuador possesses ca. $50 \%$ of the species belonging to the mesophragmatica group.

External morphological analysis (BRNCIC \& KOREFSANTIBAÑEZ, 1957) showed that, except the sibling species D. gaucha and D. pavani, the remaining species of mesophragmatica group can be identified analyzing male terminalia and external morphological characteristics. BRnCIC \& KoreF-SANTIBAÑEZ (1957) presented a key for six species of mesophragmatica group (D. mesophragmatica, D. gaucha, D. pavani, D. altiplanica, $D$. orkui and D. viracochi) based on external morphological characteristics which have allowed to observe three groups, although these are not evident in the key: the first, species are dark brown and have divergent basal scutellars (D. mesophragmatica, $D$. altiplanica and $D$. orkui), the second, species are dark brown and have convergent basal scutellars $(D$. viracochi), and the third, species are light brown and have divergent basal scutellars (D. gaucha and $D$. pavani). Morphological analysis of male terminalia (NACRUR, 1958) of the same six species showed that in some cases, male terminalia is not the best parameter to identify species of this group. However, the following external morphological differences are observed: $D$. gaucha and D. pavani are the lightest, D. mesophragmatica and $D$. orkui are the darkest and D. viracochi is dark, with convergent basal scutellars and 7 branches in the arista, including the terminal fork (NACRUR, 1958).
Based on the direction of basal scutellars, NACRUR (1958) proposed to divide the mesophragmatica group into two subgroups. This proposal is formally accepted in the present paper, and the mesophragmatica group has been divided into the mesophragmatica subgroup including eleven species with divergent basal scutellars and the viracochi subgroup including two species with convergent basal scutellars.

Cytological (BRNCIC et al., 1971) and isozyme data (NAIR et al., 1971) have showed the presence of three lineages in mesophragmatica group: the first one formed by $D$. mesophragmatica, D. brncici and $D$. gasici, the second $D$. viracochi, and the third D. gaucha and $D$. pavani. This three lineages coincide, in part, with observations of BRNCIC \& KoREF-SANTIBAÑEZ (1957) and NACRUR (1958) about external characteristics. Relationships in mesophragmatica group are not clear yet. Additional cytological, ethological and ecological studies will help to clarify the phylogenetic relationships in this species group, specially among species which do not have differences in the male terminalia morphology but present reproductive isolation that has allowed to inhabit in simpatry.

Morphology of the terminalia of Ecuadorian new species was compared with populations of $D$. mesophragmatica and D. pavani from Ecuador. Characteristics of aedeagus showed conspicuous differences that allowed to identify the new species, whereas epandrium and hypandrium showed similar characteristics. Three species, D. gaucha, D. pavani and D. amaguana, have outer peg-like setae in the surstylus, which is an important difference compared to the other species of the group. The outer peg-like setae are absent in the surstylus of $D$. shyri and D. mesophragmatica. The prensisetae are organized in a single row in both species, however, the number of prensisetae and the size of the inner setae are greater in D. shyri.

Flies of an isofemale line of $D$. pavani from Guayllabamba (Pichincha-Ecuador) were morphologically compared with those of a stock of $D$. pavani (code 15070.1241.0) received from the National Drosophila Species Resource Center (at Ohio, USA). Both D. pavani stocks presented similar characteristics: overall length $4.5 \mathrm{~mm}$, wing length $2.7 \mathrm{~mm}$ and the costal index 3.4 , except the phallosomal index that in the first is 1.27 and in the latter is 1.62. All flies were analyzed 15 days after emergence.

Acknowledgments. To Dr. Laura Arcos Terán, Facultad de Ciencias Exactas y Naturales of Pontificia Universidad Católica del Ecuador (PUCE), who supported this research; Dr. Renato Valencia and Catalina Quintana, who kindly allowed us to work in the botanical plot, Dr. Patricio Ponce, Ana Beatriz Mafla and Hugo Romero-Saltos of PUCE. To Dr. Carlos Ribeiro Vilela, Universidade de São Paulo and Dr. Raúl Godoy, Universidad de Chile for invaluable comments and helped with the translation of this manuscript into english. Idea Wild for the materials donated and the staff at the Laboratorio de Genética Evolutiva (PUCE) for their assistance.

\section{REFERENCES}

Brncic, D. \& Koref-S AntiBañez, S. 1957. The mesophragmatica group of species of Drosophila. Evolution, Lancaster, 11:300-310 
Brncic, D.; Nair, P. S. \& Wheeler, M. R. 1971. Cytotaxonomic relationships within the mesophragmatica species group of Drosophila. Studies in Genetics, University Texas Publications, Austin, 6:1-16.

NACruR, J. 1958. Genitalia masculina de Drosophila do grupo mesophragmatica (Diptera). Revista Brasileira de Biologia, Rio de Janeiro, 18(3):243-249.

NaIR, P. S.; Brncic, D. \& KoJima, K. 1971. Isozyme variations and evolutionary relationships in the mesophragmatica species group of Drosophila. Studies in Genetics, University Texas Publications, Austin, 6:17-28.

Rafael, V.; Arcos, G. \& Arcos, L. 2000. Ecología y distribución del género Drosophila en Guayllabamba y el Quinche, provincia de Pichincha-Ecuador. Revista de la Pontificia Universidad Católica del Ecuador, Quito, 65:130-155.

Rafael, V. \& Vela, D. 2000. Drosophila distribution in Ecuador. Drosophila information Service, Norman, 83:85-88.
Vela, D. \& Rafael, V. 2001. Ocho nuevas especies del grupo tripunctata, género Drosophila (Diptera, Drosophilidae) y el registro de $D$. paraguayensis en el Bosque Protector Pasochoa, Pichincha-Ecuador. Revista de la Pontificia Universidad Católica del Ecuador, Quito, 66:91-120.

Vilela, C. R. 1983. A revision of the Drosophila repleta species group (Diptera, Drosophilidae). Revista Brasileira de Entomologia, São Paulo, 27(1):1-114.

Vilela, C. R. \& B̈̈chli, G. 1990. Taxonomic studies on Neotropical species of seven genera of Drosophilidae (Diptera). Mitteilungen der Schweizerischen entomologischen Gesellschaft, Neuchâtel, 64 (suppl.):1332 .

2002. On the identity of four poorly known species of Neotropical Drosophilidae (Diptera). Mitteilungen der Schweizerischen entomologischen Gesellschaft, Neuchâtel, 75(3-4):197-210. 